RPA Journals
ITHJ

International Tourism and Hospitality Journal

Journal Homepage: https://rpajournals.com/ithj

\title{
The Potentials of 'Travel Bubble' to Re-Establish the Industry of Travel and Tourism: A Study on the Contribution of the Hotels and Restaurants in Nuwara Eliya, Sri Lanka
}

\author{
S. S. N. Ariyawardana \\ Open University of Sri Lanka, Nawala, Sri Lanka
}

\begin{abstract}
The concept of "Travel Bubble" has been introduced as a travel solution for post COVID tourism resumes. Several countries in the world have started to experience this concept with the signatories with beyond boundaries as per the ratifications. In order to this, Sri Lanka has recently started the post COVID tourism resumes based on the concept of travel bubble in selected destinations amidst several controversial dialogues. This study evaluates the potentials and applicability of "Travel Bubble" in Nuwara Eliya focusing the hotels and restaurants based on SLTDA recommended tourism guidelines with health protocols. In this study, a questionnaire based preliminary survey has been conducted including discussions, interviews and field visit observations in the process of data collection. According to the results, the preparation of tourism guidelines and the knowledge regarding the concept of travel bubble is not satisfied. Most hotels and restaurants are being bankrupted now and they claim for much knowledge and financial support before re-establishing the tourism industry with travel bubble. Therefore, this study has made a few suggestions towards tourism resumes with travel bubble operations in Nuwara Eliya, Sri Lanka.
\end{abstract}

Keywords: Travel Bubble, Hospitality, Hotels, Restaurants, Travel and Tourism, Operations, Resume, Nuwara Eliya

Corresponding author: S.S.N. Ariyawardana; E-mail: s.ariyawardana@gmail.com DOI: https://doi.org/10.37227/ITHJ-2021-01-92

\section{Introduction}

The COVID-19 that was declared as a pandemic by World Health Organization (WHO) on 12 March 2020 has significantly overwhelmed the global economic, political and sociocultural systems within a short period of time by January 2021. Consequently, travel and tourism has been severely hit by the outbreak of COVID-19 with the shutdown of domestic and international borders worldwide. The impact of this pandemic on the industry of travel and tourism will be uneven since it leads the international economy towards a recession. As reported by The United Nations World Tourism Organization (UNWTO) the international tourist arrivals are estimated to decline by $58 \%$ to $78 \%$ for the whole year of 2020 causing a loss of US\$ 1.2 trillion in export revenues from tourism and 120 million direct tourism job cuts representing seven times the impact of September 11 marking the 
largest decline in the history (UNWTO, May 2020). According to the latest tourism data released by UNWTO, destinations welcomed 900 million fewer international tourists between January and October in 2020 when compared with the same period of 2019. This translates into a loss of US\$ 935 billion in export revenues from international tourism, more than 10 times the loss in 2009 under the impact of the global economic crisis. Moreover, Asia and the Pacific, the first region which is suffered from the impact of the pandemic and the one with the highest level of travel restrictions up to date, which shows a $82 \%$ decrease in arrivals in the first ten months of 2020 (UNWTO, December 2020). Thus, the most economies which are highly depended on the industry of travel and tourism have been collapsed by the beginning of 2021 due to the domestic and international cross boarder restrictions lifted.

On this background, the concept of 'Travel Bubbles' is being started to be put in place to re-open the tourism industry among certain countries in a few regions taking into consideration their epidemiological situations. Travel bubble will allow quarantine-free travel between countries re-opening cafes, pubs, bars, hotels, and other businesses powered by tourists and business travelers. Re-building these markets would lead a tourism boom of hospitality businesses and tourism-dependent economies. Following this concept, Singapore opened a travel corridor with New Zealand and Brunei on 1 September 2020, allowing quarantine-free travel. Hong Kong (China) is discussing travel corridors with eleven destinations while Japan relaxing its re-entry restrictions to foreign residents on 1 September 2020 (UNWTO, August/September 2020).

With parallel to the world order, Sri Lanka has launched a pilot project to bring the international tourists under the concept of travel bubble to initiate re-opening the tourism industry in Sri Lanka amidst pandemic disorders. The so-called travel bubble is operated under the minimum restrictions for air travel between certain countries that have controlled the spreading virus. As the first step of this project, a several clusters of Ukraine tourists arrived Mattala Airport, Sri Lanka starting from 28 December 2020. Hereby, all the tourists were subjected to a screening test and some of them were identified as COVID-19 positive. In order to the instructions given by the Sri Lankan Government, the infected tourists were isolated at their respective hotels (Anthony, 2020). Following these procedures, a few Ukraine groups have visited Sri Lanka by the mid of January 2021. These tourists have been allowed to travel without the 14-day quarantine period as they will not have direct contact with the local community. They have proceeded on Jeep Safaris at Yala National Park and after they visited two tourist attractions of Cultural Triangle (Sigiriya and Polonnaruwa) that were temporarily suspended for the local people due to the scheduled tours of Ukrainian Groups in Sri Lanka (Velrajh, 2021). As Sri Lanka Tourism Development Authority (SLTDA) reported, these groups have enjoyed Whale Watching, Mirissa using private boats and 28 jeep safaris were undertaken without any prior notice or approval from SLTDA (Hamza and Kotelawala, 2021). Therefore, post COVID tourism operations based on the concept of travel bubble have become a controversial debate in contemporary Sri Lanka.

This study will examine the potentials of the hospitality industry in Nuwara Eliya to implement the travel bubble concept since Nuwara Eliya is one of the most significant tourism hotspots in Sri Lanka. The hospitality sector is largely operated in Nuwara Eliya and it could be an ideal destination for pledging this concept in post COVID tourism operations. However, the present study reveals that majority who are employed in the hospitality sector in Nuwara Eliya do not have a sound awareness, knowledge and preparedness in practicing the proposed concept. With the purpose of obtaining a better 
understanding of this issue, the contemporary study is based on a few research questions. These questions will be addressed through a preliminary survey which was carried out with the participation of executive, managerial and ground level staffs of hotels and restaurants in Nuwara Eliya. The major research questions of this study as follows:

RQ1: How is the preparedness of hotels and restaurants for the post COVID Tourism operations based on "Travel Bubble" concept in Nuwara Eliya?

RQ2: What are the barriers and difficulties faced by the hotels and restaurants implementing health protocols during the "Travel Bubble" operations?

These questions will emphasise that the comprehensive knowledge and awareness regarding the concept of travel bubble will be important to the hospitality sector in the future tourism operations in Nuwara Eliya. Hence, this study discourses the limitations, restrictions and capacities of hotels and restaurants in this destination to promote and practice the concept of travel bubble in the future.

\section{Literature Review}

The concept of "Travel Bubble" is quite novel for Sri Lanka. But this term has been transmitted since past in the world to identify the concentrated geographic area of touristoriented facilities and attractions which is separated from its surrounding environment by spatially or psychologically created boundaries. This term has been introduced in numerous senses using several words. The first word of the "Bubble" in the literature of tourism was written in Cohen's (1972) seminal piece on tourist typologies. The term "Bubble" was used at the first time in the context of mass tourism by Cohen. First, he applied this term for the environment to describe the "Environmental Bubble" as a familiar, comfortable microenvironment within a novel, foreign macro environment. Moreover, Weaver (2005) has defined environmental bubbles as "enclosed spaces that shield tourists from potentially unpleasant experiences....... operated for the exclusive use of tourists". Environmental bubbles are consisted of resort complexes, theme parks, tour buses, cruise ships, etc.

Aftermath, the term "Tourist Bubble" is derived from the concept of "Environmental Bubble". Smith (1977) describes the tourist bubble from the perspective of the tourist experience. He explains the experience of tourist bubble as "being physically 'in' a foreign culture while socially 'outside' the culture". Jacobsen (2003) examines the relevance of the tourist bubble in the context of inter-European travel and he defines the tourist bubble as "a territorial and functional differentiation and an expectation of (European) holidaymakers going abroad". The primary expectation of these tourists was a sense of familiarity in terms of food, lodging, and language.

Carrier and Macleod (2005) applied the tourist bubble to an all-inclusive resort in the Dominican Republic. This bubble was spatial; tourists could visit local villages, but residents were not permitted on the resort property. Further, these authors describe a psychological tourist bubble where supposed "eco-tourists" were unaware of the measures that had been taken to create their resort namely, that the construction of the resort displaced an entire village and kept local residents away from reaching the beach.

This study is based on the concept of "Travel Bubble" which is currently being practiced by certain countries in the world. As the travel restrictions were slowly lifted, several countries started to re-establish their travel and tourism arrangements between 
neighboring countries by using the term "Travel Bubble". Travel bubble could be introduced as an option for countries to restart tourism with other countries. This term is also referred as "Green Corridors", "Travel Bridges", "Corona Corridors" and "Travel Corridors". Travel bubble can be further defined as "agreements ratified by the signatories to open their borders to visitors from a partner economy or economies" (Dickens et al, 2020). Travel bubbles could be used for business travel or leisure travel. It is mutually beneficial and facilitates to recover trade and economy rebuilding transport sector and relationships between families and friends (Khan et al, 2020). They often specify provisions on health protocols that need to be followed when leaving and entering the territory. According to the concept of travel bubble the access can be reciprocal or only in one direction. They can be formed between two or more partners.

The first travel bubble in Asia and the Pacific was established between the Republic of China and the Republic of Korea on 1 May 2020 (Helble and Fink, 2020). Malaysia is in preliminary discussions with six countries on possible implementation of 'Travel Bubble' and to introduce the concept of 'Green Bubble' that eases travel restrictions between two or more countries with relatively low COVID-19 cases, allowing its citizens to travel to Malaysia (vice-versa) without a 14-day quarantine upon testing negative for COVID-19. Consequently, Malaysia eases travel restrictions between countries within the 'Green Zone', while allowing medical tourist to enter the country (UNDP, 2020).

The forthcoming sections of this study will be based on above conceptual framework. This basement will be useful to grasp a successful outcome of this study. These concepts will be important to make suggestions and recommendations for the hospitality sector in Nuwara Eliya implementing the concept of travel bubble in the future tourism operations.

\section{Research Methodology}

This study is based on the contribution of hospitality sector to implement the suggested concept of "Travel Bubble" in Nuwara Eliya during the pandemic period in Sri Lanka. In this case the study evaluates the procedures and methods taken by the hotels and restaurants to face with tourism operations basing the concept of travel bubble in Nuwara Eliya. Hereby, nine hotels and five restaurants that were registered under SLTDA have been taken into consideration as the basic samples for the study. These eleven hotels were categorized under four stars, three stars and one star while seven restaurants were categorized under A and B grade by SLTDA. In addition, randomly selected two hotels and two restaurants (were not under the registration of SLTDA) in Nuwara Eliya city have been considered as samples in this study.

\section{Questionnaire Design}

By following Sri Lanka tourism guidelines and health protocols recommended by SLTDA, a questionnaire consisted of 31 questions was prepared. 22 questions out of 31 questions were formulated to discover the preparedness of the hotel sector to implement the recommended health protocols and guidelines by SLTDA. Each question relevant to this section were entailed with 'Yes' and 'No' questions. The questions focus on different recommended practices on health protocols categorized under few areas as recommended by SLTDA under tourism operational guidelines chapter 4: 'Accommodation Sector' (SLTDA, 2020). They are Guest room corridors and lift lobbies, Restaurant, Kitchen conditions, Buffet setup and services, Gym and treatment facilities, Bars, Swimming pool, Banquet operations etc. The remained questions were formulated to measure the 
knowledge of the hoteliers regarding the "Travel Bubble" concept and financial crises they have met with the outbreak of COVID-19 pandemic.

Moreover, the discussions and interviews with the managers and hotel owners were helpful to trace their ideas regarding the concept of "Travel Bubble" and the post COVID tourism operations. In addition, the observations in the field visits were important to observe day today practices of hotel staff following the health protocols.

\section{Data Collection}

This survey was basically done through the field visits following health guidelines given by medical authorities in Sri Lanka. 11 hotels and 07 restaurants were participated in this survey. 06 (A, B, C, D, E, F) hotels and $02(\mathrm{G}, \mathrm{H})$ restaurants completed the survey while 03 hotels and 03 restaurant are answering partially. Other 04 participants abandoned the survey. These data were collected around one week at the beginning of January 2021 in a background of "Travel Bubble" operations are lifting other areas in Sri Lanka.

\section{Results and Analysis}

This section will reveal the most significant information of this study gathered using the questionnaire survey with the participation of hotels and the restaurants in Nuwara Eliya. Hereby, it will primarily evaluate the current operations of the hospitality sector before and after COVID, the knowledge of the hoteliers regarding the concept of "Travel Bubble", the preparedness and the practice of tourism guidelines with health protocols recommended by SLTDA. This section will be continued under a few sub-sections as follows.

\section{The Impact of COVID-19 Outbreak on Hospitality Sector in Nuwara Eliya}

As the first step, this study will observe the contemporary tourism procedures of the key components of hospitality sector in post COVID-19 in Nuwara Eliya. Basically, this section will submit a comparative analysis regarding the institutional and financial background focusing hotels and restaurants before and after COVID-19 pandemic. It will analyze the impact of the pandemic on the employment and the financial sectors of the hospitality industry in Nuwara Eliya. Considering the employment rate of the hotel sector including restaurants, figure 1 shows a clear decline of the number of employed staff in every hotel under 1 star, 3 stars and 4 stars categories after COVID-19. Most of them were temporarily terminated with pay and without pay based on the nature of their services and some of them were resigned due to the issues stimulated with salary payments. 
Figure 1: Number of Employers of in the hotel sector in Nuwara Eliya - Executive Level, Managerial Level and Ground Level Staff 2019-2021 (before and after COVID-19 pandemic)

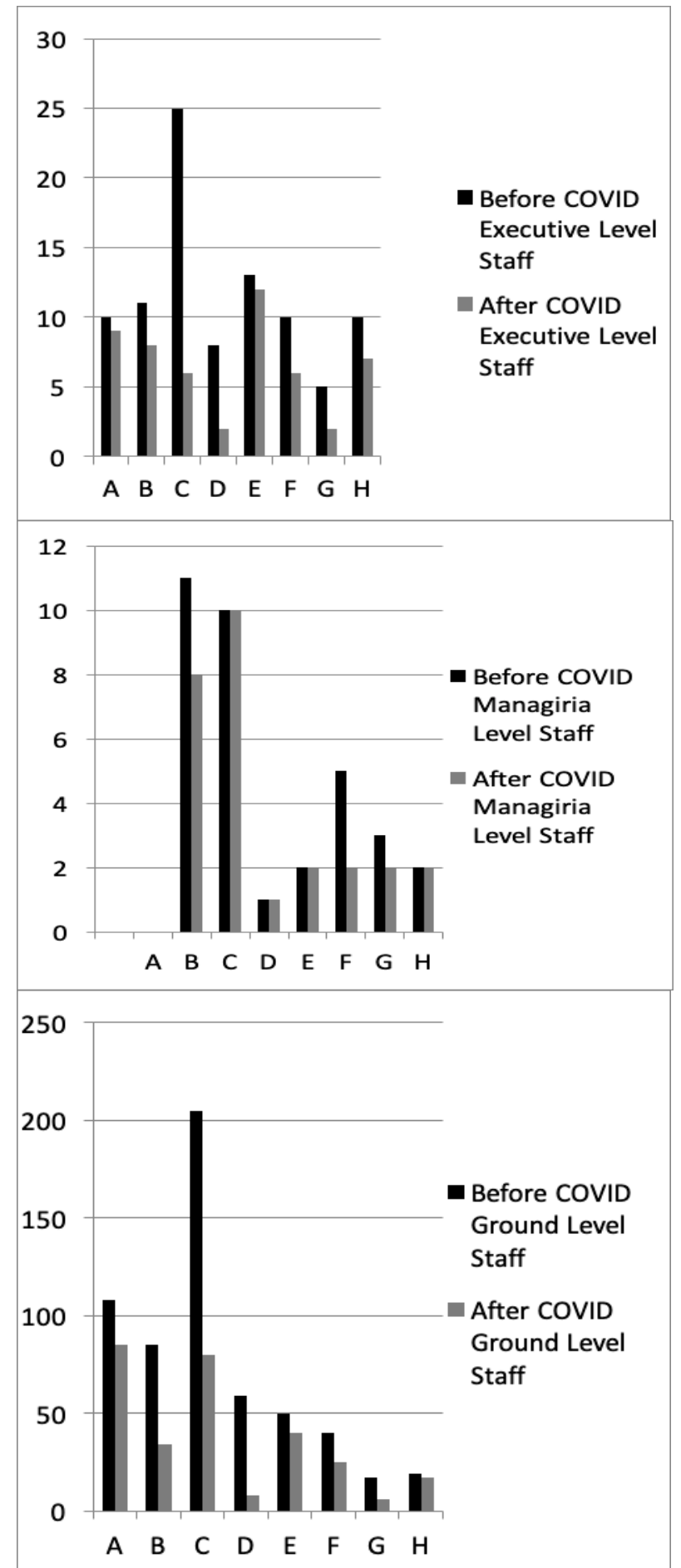

$$
\begin{aligned}
& \text { A - } 4 \text { Stars } \\
& \text { B - } 4 \text { Stars } \\
& \text { C - } 4 \text { Stars } \\
& \text { D - } 4 \text { Stars } \\
& \text { E - } 4 \text { Stars } \\
& \text { F - } 3 \text { Stars } \\
& \text { G - } 3 \text { Stars } \\
& \text { H - } 1 \text { Star }
\end{aligned}
$$

According to above statistics, majority of 3 stars and 4 stars hotels have recorded $40 \%$ $60 \%$ unemployment rate while other hotels bellow 3 stars category including restaurants have reported less than 20\% unemployment rate in Nuwara Eliya. The major reason for this situation could be the most of 4 stars and 3 stars hotels have recruited their staff with the employers coming from far-off the working area. With the cut-off of salaries and the 
staff of the large-scale hotels due to the pandemic most of the employers had to return their hometowns since they are being suffered with the pressure of upraised living expenses in Nuwara Eliya. This high unemployment rate is included with the employers who have been resigned and terminated by the hotel. Therefore, re-establishing tourism with travel bubble will be beneficial for the work force in hospitality sector in the future.

Evaluating the current operations of the hotel sector, it would be more important to examine the income levels of the hoteliers that they have earned per month before and after the pandemic (Figure 2). Hereby, this study considered the hotels registered under 4 stars, 3 stars and 1 star category in Nuwara Eliya.

According to the figure 2, it clearly shows that majority of the hotel sector have been bankrupted with the restrictions uplifted over travel and tourism due to the pandemic. It is clearly visible in the chart that the income levels of $75 \%$ hotels have been declined $50 \%$ or more in Nuwara Eliya after COVID-19 pandemic. Majority of these hotels are large-scale hotels fall under 4 stars and 3 stars categories. This situation has been affected over the good and service suppliers including laundry services supported by the hotel sector. Especially, large and small-scale professional flower providers in Nuwara Eliya have lost their livelyhoods with the suspension of hotel operations. Fortunately, around $25 \%$ of hoteliers are still maintaining their income same as before COVID-19. But it is not a satisfied figure considering the majority of hotel sector that was financially affected by the pandemic.

On this background, $66.6 \%$ of hotels that were under SLTDA have been granted a grace period for their bank loans and this period was ranging from 6 months to 12 months. The government has reduced the tax payment rates for $50 \%$ of hotels in Nuwara Eliya. Most of them are ranging in between 4 stars and 3 stars categories. $50 \%$ of micro level hotels and restaurants under 1 star category were not granted any benefit from the government or provincial authorities during this critical period. $25 \%$ of SLTDA registered hotels and restaurants were temporarily closed. Most of these bankrupted hotels and restaurants were operated with foreign tourists other than the local tourists. Therefore, the concept of travel bubble will be helpful and important to re-start these hotels with tourism operations in near future.

\section{Preparedness of Hospitality Sector to Practice the Concept of "Travel Bubble" in the Future}

This section will continue with the preparedness of the hotels and the restaurants in Nuwara Eliya for the suggested operations with the concept of "Travel Bubble" in Sri Lanka. Hereby, this survey primarily evaluates the knowledge of the hotel sector regarding the concept of 'Travel Bubble' introduced by the Sri Lankan government. Only $44.6 \%$ hotels under SLTDA have been aware of this concept and among this cluster there were only $50 \%$ of hoteliers those who had a satisfied knowledge about the concept. Both hotels and restaurants that are registered under SLTDA and not registered under SLTDA respectively $75 \%$ and $65 \%$ have been aware of the concept through the public media. However, only $12.5 \%$ hotels have been aware of the concept through SLTDA. Considering most of the hotels in Nuwara Eliya, $42.8 \%$ maintain a satisfied knowledge of the concept of travel bubble and $48.2 \%$ of the hotels need more knowledge regarding this concept.

In the next stage, this study considers the contribution and awareness of hotel sector regarding 'Sri Lanka Tourism Operational Guidelines with Health Protocols' to achieve the purpose of the concept of travel bubble in Nuwara Eliya. Hereby, SLTDA recommended guidelines and health protocols under the 'accommodation sector' and 'tourist facilities and 
services sector' will be determined. It was recorded through the survey that all the hotels, almost 100\% have been aware of the 'Sri Lanka Tourism Operational Guidelines with Health Protocols' introduced by SLTDA. This section will evaluate how the hotel sector use their knowledge regarding these guidelines in practicing post COVID tourism resumes to prosper the concept of travel bubble in Nuwara Eliya.

As the first step, this study analysis the staff occupancy level in tourism operations. Hereby, $62.5 \%$ hoteliers are maintaining between $51 \%-75 \%$ staff occupancy rate in their post COVID tourism resumes exceeding 50\% staff occupancy rate recommended by SLTDA. $12.5 \%$ of hotels are maintaining below $50 \%$ of staff in their tourism operation resumes as recommended. Rest of $25 \%$ of hotels avoided from responding this question. It implies that majority of hotels did not realize and consider this condition that is necessarily important for the travel bubble concept to maintain physical distance.

This survey further found that $87.5 \%$ of hotels are maintaining 1 or 2 isolation rooms which are equipped with necessary medical equipment and Personal Protection Equipment (PPE) to occupy in an emergency. The majority who are maintaining isolation rooms are fallen under 4 stars category. The rest of $12.5 \%$ have avoided from responding. They might not have a satisfied financial background to maintain isolation rooms with well-equipped PPEs as recommended since the most of these hotels and restaurants fall under 3 stars category and below.

SLTDA has recommended a 'Rapid Response Team' and a 'Management Team' for every hotel to deal with COVID pandemic tourism operations while preventing incidents, effectively managing cases and mitigating impact among all stakeholders of the premises. In Nuwara Eliya, 71.4\% hotels function with both 'Rapid Response Team' and 'The Management Team'. Rest of the hotels (28.6\%) are functioning only with the 'Management Team' those who are not operated under SLTDA registrations. Therefore, it is important to aware those hoteliers by the relevant authorities regarding these two terms. It might be useful to conduct post COVID tourism operations safe and mitigate the impact for others.

Moreover, SLTDA has recommended encouraging the use of paperless systems for check-in and billing procedures to minimize the use of paper wherever possible. This survey discovered that $50 \%$ of hotels are still delivering their check-in and billing systems manually by using papers. $25 \%$ of those hoteliers are SLTDA registered tourist establishments. $37.5 \%$ of hotels are using online and electronic systems in check-in and billing procedures in Nuwara Eliya. However, they are not registered as SLTDA tourist establishments. $12.5 \%$ of hotels avoided from responding this matter. Further, designated telephone facilities for the guests have been recommended by the SLTDA. However, this survey reveals that $87.5 \%$ hotels have been provided this facility except restaurants in Nuwara Eliya. In the concept of travel bubble Sri Lankan government encourages the tourists to travel under minimum contacts with the external society and manual systems maintained by the hotels since it may spoil this concept. Therefore, relevant authorities and the hotel managements should pay their attention to establish online check-in/check-out and payment facilities for their customers even during this critical period as recommended.

Considering elevator operations, $60 \%$ of hotels have recommended $4-5$ passengers and above in the elevator while $25 \%$ recommend 2 persons at once inside the lift per turn. However, according to SLTDA tourism operational guidelines, this number of passengers should be limited at least 2 persons inside the lift not facing each other. Hence, hotels should be more responsible regarding the guidelines provided since the concept of travel 
bubble may interrupt through such miss-functions occurred due to mal-awareness of the hoteliers.

Considering the guidelines given by SLTDA for 'Guest room corridors and lift lobbies', 63.6\% hotels are being followed all the relevant guidelines provided in the declaration of Sri Lanka Tourism Operational Guidelines with Health Protocols (SLTDA, 2020). The rest of $36.4 \%$ hotels have refrained from responding. It shows that $2 / 3$ of hoteliers have a sound awareness of maintain guest room corridors and lift lobbies according to the recommended health protocols.

The procedures recommended by SLTDA for guest room cleaning process were subjected to examine in this survey with the daily operations of the hoteliers in Nuwara Eliya. $50 \%$ of hotels are keeping balcony door and outside windows opened during the cleaning process while $42 \%$ are being avoided. $100 \%$ are not using $\mathrm{A} / \mathrm{C}$ sanitizer tablets as recommended and only $13 \%$ hotels encourage to clean $\mathrm{A} / \mathrm{C}$ systems and the filters. The procedures regarding sanitizer providing in every room, cleaning the guest amenities by using dishwashers, displaying sticker and tent card in the room confirming disinfection are carried out by $38 \%$ of hotels while $58 \%$ are neglecting those procedures. $50 \%$ of hoteliers are using vacuum cleaners in the cleaning process while $62 \%$ disinfecting all devices inside the room including walls, floors and ceilings. These information emphases that, majority of the hoteliers do not follow the recommended procedures in guest room cleaning process.

This survey further evaluates the restaurant operations of the hotels in Nuwara Elya while in tourism resumes. Hereby, the $100 \%$ of hotels are using traditional Sri Lankan greeting "Ayubowan" to welcome their guests while practicing 1.5 physical distance and wearing face masks and PPEs as required. This will be a positive preparation of the hotel sector to operate with the travel bubble in Nuwara Eliya. However, 57.1\% hotels do not provide salt and pepper packets instead of shakers inside the restaurant. In this case, the guests will have to use same shaker when they are consuming salt and pepper. Consequently, this could be a possible media to contaminate other person by the virus although they are in the travel bubble outside of the hotel/restaurant.

Considering buffet setup and services of the hotels, $30 \%$ of hoteliers do not provide sneeze guards in buffet services. Most of those hotels fall under 3 stars category and bellow. These hoteliers might avoid providing sneeze guards because of the expenses will not be manageable with their income for facilitate such arrangements. As well the clear glasses or plastic shields were also arranged by $62.5 \%$ hotels in Nuwara Eliya. $50 \%$ of them are registered under SLTDA. 100\% hotels have appointed dedicated staff to serve each item in the buffet avoid guest handling spoons and tongs as recommended. This is a satisfied condition towards the operations with the concept of travel bubble in Nuwara Eliya.

SLTDA has provided guidelines for the banquet operations for the hoteliers. In this case this study has revealed $29 \%$ of hotels are not operated with banquets. The basic condition for the banquet operations imposed by SLTDA is that "seating in the venue should be arranged keeping the 1.5 meter distance between chairs as per the recommended safe distancing; however, the maximum number of guests allowed inside a venue should be limited to $1 / 3$ of the full capacity of banquet hall or 100 pax, whichever is lower" (SLTDA, 2020). According to this condition, 1.5 meter distance between chairs is uplifted with $100 \%$ hotels in Nuwara Eliya. But 50\% hotels do not realize the provision of 'the $1 / 3$ of the full capacity of banquet hall or 100 pax, whichever is lower is allowed inside the venue'. $100 \%$ hotels do not recommend dancing and dancing floor during post COVID tourism operations in Nuwara Eliya. 
Moreover, this survey determined the ideas of hotels and restaurants regarding tourism operations guidelines to implement the concept of "Travel Bubble" in Nuwara Eliya. 57.1\% have claimed for financial support to implement the concept along with the operational guidelines while $28.5 \%$ completely agree with all the recommendations. $14.2 \%$ have avoided from responding. The majority who needs the financial support were 3 stars and 1 star hotels along with the restaurants.

Finally, this survey resulted that the unemployment rate of the hospitality sector in the post COVID-19 tourism resumes has been recorded a clear-cut decline especially in hotel sector fall under 4 stars and 3 stars categories and considerably the restaurants in Nuwara Eliya. As well the income levels of the most hotels and restaurants have been dropped down exceeding 50\% ratio after COVID-19 pandemic compared to before the pandemic. On this background, most financial benefits that are grace period for bank loans, tax deductions and other provincial remunerations were granted for the large-scale hotels that are hotels 4 stars and 3 stars including the hotels registered under SLTDA. Unfortunately, small-scale hotels and restaurants below 3 stars category have not been granted satisfied financial benefits from government authorities. Moreover, a few hotels and restaurants were completely shut down due to the financial difficulties of maintenance. Considering this background, it reveals that the hotels and restaurants related with the hospitality sector in Nuwara Eliya have currently been bankrupted and mal-functioned due to the travel and tourism pause during last pandemic period.

Basing on this context, this study further investigated the knowledge and awareness of the hoteliers regarding the concept of "Travel Bubble" before post COVID tourism resumes in Nuwara Eliya. The majority of hotels and restaurants were not aware with a satisfied knowledge regarding the concept. Hence, they do not show an adequate preparedness for the future tourism operational resumes with the concept of travel bubble. The absence of a formal program or mechanism to function with the concept in the future will be occurred significant drawbacks with travel bubble operations in post COVID tourism industry in Nuwara Eliya.

Finally, this survey further revealed that most hoteliers and restaurants have been aware of "Sri Lanka Tourism Operational Guidelines with Health Protocols (SLTDA, 2020)". Majority of hoteliers are trying to follow those recommended criteria in Nuwara Eliya. Unfortunately, they do not have a clear idea about the way they apply those criteria in the operations with "Travel Bubble" in post COVID tourism resumes. However, majority of hoteliers agree to operate with the "Travel Bubble" concept following recommended health protocols and guidelines. Hence, they have claimed for considerable financial support and knowledge regarding the concept to facilitate and serve the tourists who are traveling under the travel bubble in post COVID tourism resumes in Nuwara Eliya. In conclude, the concept of "Travel Bubble" will be well applicable in Nuwara Eliya to re-establish the tourism operations following health protocols. In this case, it might be more successful, if the relevant authorities could provide formal solutions for contemporary financial crises of the hotel and restaurant sector while launching an awareness program before post COVID tourism resumes under the concept of "Travel Bubble" in Nuwara Eliya.

\section{Research Limitations and Further Directions}

The sample of this survey is consisted of 11 hotels under 4 stars, 3 stars, 1star categories and 07 restaurants that are categorized under grade ' $A$ ' and ' $B$ ' including hotels and restaurants registered and not registered under SLTDA. However, there are only 06 hotels and 02 restaurants were actively participated the survey and others avoided the survey. 
Figure 3 and 4 indicate the way of the participation of the hotels and restaurants for this survey in Nuwara Eliya.

According to figure 3, it shows that $63.63 \%$ hotels were actively participated the survey while $36.37 \%$ are avoiding the survey in Nuwara Eliya. However, the participant rate of restaurants in Nuwara Eliya is $28.50 \%$ while $71.50 \%$ avoiding the survey (Figure 4). Hereby, 4 stars hotels provided a fair contribution while 3 stars, 1 star and the restaurants expressing a mal participation. The data collection of this survey is limited, since a few hotels and restaurants chosen as samples were closed due to the COVID-19 pandemic. Some hotels discouraged and avoided answering the questionnaire though they are available at the premises. Certain hotels and restaurants partially replied the questionnaire since they do not have any idea regarding the concept of "Travel Bubble" and post COVID tourism operations. Therefore, this research has been limited for $50 \%$ of sample hotels and restaurants in the survey. Mal participation for such surveys may distract providing accurate and reliable information for the responsible authorities to implement forthcoming programs and projects in the field. Therefore, they will be misguiding in making future decisions.

This research was narrowed to evaluate the contribution of basic figures of hospitality sector which are hotels and restaurants in Nuwara Eliya. The further directions for the future research regarding the "Travel Bubble" suggest examining the contribution and ideas of other stakeholders such as ordinary people, tourism-based service providers including travel sector and other governing bodies related to hospitality industry in Nuwara Eliya. Moreover, to extend the problem identification, future studies could examine the difficulties and constraints face by the tourists who travel with the bubble. Additionally, future research can build on assessing the potential of the concept of travel bubble to undergo with tourism operations under minimum contamination of virus within and without the bubble. Similarly, the future studied could be based on examine the potentials of travel bubble concept used in ecotourism operations in Nuwara Eliya since this area is one of the most authentic destination for ecotourism in Sri Lanka. Ecotourism highly recommends maintaining inter-relationships between tourists and the host communities in the area other than traditional tourism operations. Therefore, it will be important to measure the applicability of the concept of travel bubble for ecotourism practices in Nuwara Eliya. On this background, this study would be helpful to deliver diverse grounds for future research related with the concept of travel bubble in Nuwara Eliya.

\section{Conclusion and Implications}

The COVID-19 pandemic outbreak has been overwhelmed every nook and corner of the world destructing large-scale industries including travel and tourism. Therefore, most of the tourism operations occurred beyond boundaries was restricted with the rules and regulations imposed over control of the pandemic for more than one year. Consequently, the concept of "Travel Bubble" has been recognized and practiced in post COVID tourism resumes by several countries. Following those practices, Sri Lankan Government started a pilot project with the concept of "Travel Bubble" based on selected destinations in the island as a post COVID travel solution to re-establish the tourism industry in Sri Lanka. Currently, this concept is being practiced in certain tourist destinations under a few steps with the participation of several tourists' groups travelled from Ukraine. However, at the present this concept has been subjected to controversial debates due to several shortcomings occurred during the pilot project. Therefore, this study examined the potentials and the applicability of the concept of "Travel Bubble" operations in the post 
COVID tourism resumes in Nuwara Eliya especial reference with the preparedness and the obstacles faced by the hospitality sector focusing hotels and restaurants in the city area. Consequently, it resulted that the hotels and restaurants need more knowledge, awareness and financial support in the tourism resumes with travel bubble operations in Nuwara Eliya.

The implications of this study would direct the stakeholders of the industry of travel and tourism through an effective practice of travel bubble during the post COVID tourism operations in Sri Lanka. The responsible authorities such as SLTDA, Sri Lanka Hotel Cooperation and the Ministry of Tourism will be able to implement future tourism projects following these research outcomes as applicable in Nuwara Eliya. The government will gain from this study of travel bubble operations in post pandemic tourism resumes as tourism is one of major supplements to the GDP in Sri Lanka. Further, the academic scholars would be able to enrich the literature regarding future tourism based on this research in numerous phases related to the practice of travel bubble concept investigating its applicability in several tourism perceptions such as ecotourism, agro-tourism, urbantourism etc. Finally, the business community and ordinary people depended on tourism industry will be beneficial through practicing this concept in their tourism-based livelihoods while the tourists are being privileged to travel towards their dream destinations if the pandemic situation prevailed.

\section{Recommendations}

The current study suggests a few recommendations towards successful post COVID tourism resume with the concept of "Travel Bubble" in Nuwara Eliya. As an initial step, a formal coordination and a mechanism should be placed in between responsible authorities decentralized by the three major tourism governing bodies that are Ministry of Tourism, SLTDA and the Hotel Corporation. With the combination and the directions of these three institutions, formal awareness programs and workshops could be arranged for the hotels and restaurants regarding the practice of concept and the tourism operational guidelines. At the first step of this process, SLTDA registered hotels and restaurants could be used as the participants according to their services fall under the star categories. i.e. some hotels are maintaining banquets, bars, gym and treatment facilities, swimming pools etc. The program should be carried out compatible with the facilities provided by the hotels and the restaurants based on their star categories. At the end of the program, these participants will be given a certificate under SLTDA who are recommended as leading hotels and restaurants in travel "Travel Bubble" operations in Nuwara Eliya. It might build the selfconfident and inspiration in hotel sector towards the operations of the concept as professionals. Then other hotels that are not registered under SLTDA could be given the same training and the awareness under the guidance of this authorized network of hotels and restaurants at the levels of their star category.

Considering the financial crisis, South Asia tourism markets such as India, Nepal, Pakistan etc. could be encouraged to practice the travel bubble while lodging at a low cost in Nuwara Eliya. Hoteliers might be encouraged promote the quantity of tourists while maintaining the quality compatible with South Asian markets. It can be assume that South Asian tourism market could be maintained at a lower cost than Europe and other markets. Promoting South Asian market will be more beneficial for small-scale hotels and restaurants.

Most hotels and restaurants are uncomfortable with maintain a full equipped isolation rooms for an emergency. Therefore, the responsible authorities could be able to 
establish a common designated medical center fully equipped with PPEs only for the tourists for all hotels and restaurants to occupy in an emergency situation based on tourism operations. This might be beneficial even for small-scale hotels and restaurants that are unable to maintained fully equipped isolation rooms for their guests.

The hotels and restaurants could arrange individual transport network for their guests to minimize external society contacts outside their bubble. This transport network could be arranged from the airport to the hotel by using recommended travel company or transportations certified by the authorized hotels as above mentioned or the government. The cost for such a network could be sharing among tourists, relevant hotel and the government partially.

It will be important to introduce a customized tour itinerary for the tourists who travel with the travel bubble including recommended tour destinations in the area through provincial tourism authorities. This kind of project would be helpful to minimize the contamination of travel bubble and the external society and also will be useful to easily detect the affected parties in any COVID positive case in the area related to the relevant tourist group. The information and the recommendations of this study would be supportive for pertinent stakeholders to respond in post COVID tourism resumes. Therefore, this review would be useful to operate the concept of "Travel Bubble" in the future with minimum failures in Nuwara Eliya, Sri Lanka.

\section{Acknowledgements}

This paper and the research behind it would not have been possible without the exceptional support of Mr. Mahinda Kumara, The Chairperson, Alpine Hotel, Nuwara Eliya and the staff. His knowledge and the countless support were admired during the field visit. I am indebted Mr. Nishan Deshapriya Adhikari, The Excise Officer, The Excise Department; Nuwara Eliya extending his helping hand to accommodate for several days to accomplish the field survey in Nuwara Eliya. Further, I am grateful to all the hotels and restaurants supported providing valuable information and sharing experiences. Finally, my hearttouching gratitude goes to my belloved parents, kids and soul-mate for their patience and support throughout this task.

\section{References}

Anthony, V. (2020). 'Spotlight on travel bubbles and reviving tourism', available at: http://www.themorning.lk/spotlight-on-travel-bubbles-and-reviving-tourism/. (Accessed 15 January 2021)

Carrier, J.G., and Macleod, D.V.L. (2005). Bursting the bubble: The socio-cultural context of ecotourism. Journal of the Royal Anthropological Institute, 11, 315-334.

Cohen, E. (1972). Towards a sociology of international tourism. Social Research, 39(1), 164-182.

Dickens, B. L., Koo, J. R., Lim, J. T. et al. Strategies at points of entry to reduce importation risk of COVID-19 cases and re-open travel. Journal of Travel Medicine, 27(8),

Hamza, M., Kotelawala, H. (2021). "Sri Lanka tourism regulator not provided Ukrainian travel itinerary; Sigiriya, P'naruwa trips cancelled", available at: https://economynext.com/sri-lanka-tourism-regulator-not-provided-ukrainiantravel-itinerary-sigiriya-pnaruwa-trips-cancelled-77516/\#. (Accessed 16 January 2021) 
Helble, M., Fink, A. (2020). Reviving Tourism amid the COVID-19 Pandemic1. C Asian Development Bank. http://hdl.handle.net/11540/12487. License: CC BY 3.0 IGO. Retrieved from https://think-asia.org/bitstream/handle/11540/12487/revivingtourism-amid-covid-19-pandemic.pdf? sequence=1. (Accessed 20 January 2021)

Jacobsen, J.K.S. (2003). The tourist bubble and the Europeanization of holiday travel. Tourism and Cultural Change, 1(1), 71-87.

Khan, S., Tiwari, R., Natesan, S., Yatoo, M. I., Malik, Y., S., Dhama, K., (2020). International travel during the COVID-19 pandemic: Implications and risks associated with 'Travel Bubbles', Journal of Travel Medicine, 2020, 1-3. '. (Accessed 20 January 2021)

SLTDA (2020). Sri Lanka Tourism Operational Guidelines with Health Protocols, Version 1, 08 June $2020 . \quad$ Retrieved from https://www.srilanka.travel/pdf/SL Tourism Operational Guidelines.pdf (Accessed 18 January 2021)

Smith, V.L. (1977). Introduction. In V.L. Smith (ed.) Hosts and Guests: The Anthropology of Tourism (pp. 1-14). Philadelphia: University of Philadelphia Press.

UNDP (2020). Resumption of Travel. Issue 12. UNDP, Malasia. Retrieved from file://C:/Users/Dell/Downloads/Issue \%2012 \%20Resumption\%20of\%20Travel.pd f. (Accessed 18 January 2021)

UNWTO (August/ September 2020). UNWTO World Tourism Barometer, Vol. 18, Issue 5, August/ September 2020. ISSN: 1728-9246, UNWTO, Madrid, Spain - First printing: 2020 (version 18/09/20) Retrieved from https://www.eunwto.org/doi/pdf/10.18111/wtobarometereng.2020.18.1.5. (Accessed 20 January 2021)

UNWTO (December 2020). Tourism Back to 1990 Levels as Arrivals Fall by More Than 70\%. World Tourism Organization, Calle Poeta Joan Maragall 42, 28020 Madrid, Spain. Retrieved from https://www.unwto.org/taxonomy/term/347. (Accessed 16 January 2021)

UNWTO (May 2020). UNWTO World Tourism Barometer, Vol. 18, Issue 2, May 2020, UNWTO; Madrid, Spain: 2020. Retrieved from DOI: https://doi.org/10.18111/wtobarometereng. (Accessed 16 January 2021)

Velrajh, V. (2021). "Sri Lanka- Visit to Sigiriya and Polonnaruwa by Ukrainian tourists cancelled", available at: https://menafn.com/1101379202/Sri-Lanka-Visit-toSigiriya-and-Polonnaruwa-by-Ukrainian-tourists-cancelled\&source $=30$. (Accessed 17 January 2021)

Weaver, A. (2005). Spaces of containment and revenue capture: 'Super-sized' cruise ships as mobile tourism enclaves. Tourism Geographies, 7(2), 165-184. 